\title{
There is nobody to be ruled
}

\section{Praful D. Bhavsar}

Director (Retired), Space Applications Center, Indian Space Research Organisation, Ahmedabad 380 015, India

I still remember the day as if it was yesterday. It was Thursday 30 December 1971. I got up that morning, casually glanced at a magazine, and noticed a sloka.

$$
\begin{aligned}
& \text { न राज्यं न च राजासीत, न दण्डयो न च दण्डिक : / } \\
& \text { धर्मेणैव प्रजास्सर्वा, रक्षन्ति स्म परस्परम् // }
\end{aligned}
$$

\section{No state, no king, no judge and no criminal would exist if everybody lived by Dharma; for, then, people would protect each other.}

I was in a great hurry that morning. I had reached Mumbai from Thiruvananthapuram the previous evening after a long day of meetings with Sarabhai. I was in the northern suburb of Khar, and in a hurry to reach the Department of Atomic Energy's office at the Old Yatch Club in south Mumbai, finish some work there, and then rush to the Santacruz airport to meet Sarabhai to continue the discussions from the previous day. But, alas, when I reached the DAE's office, I was informed of the sad news that Sarabhai had died the previous night. The gravity of the news was still sinking in.

In those sad moments, I realized the full significance of the sloka I had read that morning. What I was not able to understand that morning, nor had been able to fully grasp during the previous two decades working with Sarabhai, was suddenly and immediately clear to me. This is what Sarabhai was trying to achieve - establish a new organizational culture in the country. Some unknown power had driven me to that fact, that Thursday morning.

There is no ruler, there is nobody to be ruled;

There is no punisher, there is nobody to be punished. All with righteous behavior, are protecting each other.

Sarabhai strongly believed in a collective responsibility.

In 1948, having finished my B Sc, I went to Pune in search of a college where I could pursue my studies towards M Sc in Physics. In Pune, I met L. A. Ramdas, Director of the Agricultural Meteorology section of the Indian Meteorology Department. He informed me of the newly started laboratory in Physics by Vikram Sarabhai in Ahmedabad and advised me to go and meet him.

\footnotetext{
*e-mail: professor.pdbhavsar@gmail.com
}

Thus, I met Sarabhai for the first time in August 1948 in a small room at the M.G. Science Institute, where the Physical Research Laboratory had been given a couple of rooms by the Ahmedabad Education Society. He was wearing white Khadi trousers with a bright green shirt, working at the glass-blower's desk with a Geiger counter. He greeted me with a smile and asked me to wait a bit until he finished repairing the Geiger counter. I was at once impressed by this young, simple, unassuming person, who fit very well with my mental image of a young experimental physicist and was ready to accept him as my teacher. He briefly interviewed me, probed my interest and motives for studying Physics, and welcomed me to his laboratory. In those days, Sarabhai was quite fond of wearing bright coloured shirts, one day a deep green, another day a bright blue one, and the next day a shirt in scarlet. He changed his style of dress later to a simple kurta-pajama and chappals, but his ever-smiling face and the twinkle in his eyes remained unchanged through all those years since I met him in those early days of the Physical Research Laboratory in August 1948.

In those early years, Sarabhai would go to Vadodara by train, every Friday, to look after his work in Pharmaceuticals. He would take one of his students along with him in the train, so as not to waste the time while on the train. We would work on a manuscript for publication, or a chapter of a student's thesis, or work on some problem under study. During such trips to Vadodara I came to know Vikram Sarabhai as a person, his feelings, his deep concern for the country, and his strong desire to make a lasting change in the pattern of our society.

He believed that science and technology thrive only in a culture which relies on horizontal control systems rather than vertical control systems. This idea, when applied to an organization meant that an individual's position in that organization was defined by their job and/or responsibility, and not by their salary. He did not believe in the superiority of an 'officer' by virtue of their salary. He believed in free exchange of ideas within an organization, where everyone discussed and talked with each other without barriers, and worked together towards the common goal. Therefore, he would be deeply hurt, and would find it difficult to understand, when sometimes some important work would get delayed, just because someone did not share the right information at the right time with another person, because they perceived it was below their dignity to approach someone who 'ranked' lower than them in the organization.

CURRENT SCIENCE, VOL. 118, NO. 8, 25 APRIL 2020 
The humblest of persons, a peon or the car driver, was able to approach Sarabhai and discuss their needs without feeling inferior, and Sarabhai would always offer them a seat and have time to discuss their concerns without being conscious of his position at the top of the organization. To him all were equal. He believed in everyone's dignity and strived to preserve it, irrespective of their status in society, which tended to be defined by the level of wealth or poverty, educational background, or social status.

Sarabhai was always ready to help anybody who he found in a difficult position. I clearly remember the day when a labourer was bringing some heavy boxes to the laboratory in a handcart and was finding it difficult to push the cart up a slope. Sarabhai immediately joined the labourer to push the cart up the slope. In those early days at the Physical Research Laboratory, when there was work being done on electronic circuits for the construction of cosmic ray telescope, there was always a need to move heavy equipment such as an oscilloscope or a heavy power source. Sarabhai would never call for help and would lift the equipment himself and move it from one room to another.

Sarabhai was also never worried about the so-called brain drain from India during the late 1950s and early 1960s. On the contrary, he would always encourage young people to go abroad to learn new science, new technologies. He was very sure of those young minds returning to India; he had a vision, he knew what these young scientists wanted, and he was able to create situations and an atmosphere that encouraged these young minds to return home to India and contribute towards the growth of the country.

During his many trips abroad, no matter how busy, he never hesitated to meet with young Indian scientists who would request to meet him. And, that one meeting was usually enough to inspire that young mind to return to the homeland to do his, or her, bit towards building newer technologies in India.

India lost this great visionary at a very young age. I believe that the tribute we can continue to pay him is to remember his approach, to work incessantly with the zeal and vigour towards the one common goal, in the way he inspired each and every one of us who had a chance to work with him.

doi: $10.18520 / \mathrm{cs} / \mathrm{v} 118 / \mathrm{i} 8 / 1180-1181$ 